\title{
A Ring-4 Chromosome in a Patient with Normal Intelligence and Short Stature*
}

\author{
RAWATMAL B. SURANA, †OHN D. BAILEY, and PATRICK E. CONEN \\ From the Departments of Pathology and Paediatrics and The Research Institute, The Hospital for Sick Children; \\ and the Departments of Pathology and Paediatrics, University of Toronto, Toronto, Ontario, Canada
}

Ring chromosomes first reported in non-neoplastic human cells by Wang et al (1962) have now been described in all human chromosome groups (Kistenmacher and Punnett, 1970). Six cases of a ring form of a member of a B-group chromosome have been described (Rohde and Tompkins, 1965; Steele et al, 1966; Carter, Baker, and Hayman, 1969; Dallaire, 1969; Faed, Stewart, and Keay, 1969; Hecht, 1969) and three of these have been thought to be a No. 4 chromosome ring (Carter et al, 1969; Dallaire, 1969; Hecht, 1969).

While investigating the cause of short stature in a 6-year-old girl, we found a self-perpetuating ring chromosome in B-group which, on autoradiographic studies, we consider to be a No. 4 chromosome.

\section{Case Report}

The girl was born to a 24-year-old primiparous mother and a 24-year-old paranoid-schizophrenic father after 42 weeks gestation. Labour had been induced.

The pregnancy had been complicated. In the first trimester the mother had developed Trichophyton verrucosum infection of the skin of her right arm and had been treated with an antifungal ointment for the duration of her pregnancy; when 8 to 9 weeks pregnant she had ingested 2 to 3 tablets of griseofulvin; $\ddagger$ and in the 5 th month surgical repair of the vaginal septum had required general anaesthesia.

The mother is $162 \mathrm{~cm}$ tall, the father $168 \mathrm{~cm}$ tall and the patient's only sib, a 3 -year-old sister, $87 \mathrm{~cm}$ tall $(<10$ th centile).

The proposita's birth weight was $2330 \mathrm{~g}$ and the head was noted to be small. During infancy she experienced frequent episodes of vomiting, loose stools, and upper respiratory tract infections. At 9 months of age her

Received 16 February 1971.

* Address reprint requests to P.E.C., Department of Pathology, The Hospital for Sick Children, 555 University Avenue, Toronto 101, Ontario, Canada.

+ Present address: Department of Pediatrics, Methodist Hospital of Brooklyn, 506 Sixth Street, Brooklyn, NY 11215, USA

‡ Fulvicin. Schering Corporation Ltd, Pointe Claire, Quebec, weight was $6.3 \mathrm{~kg}$ (<3rd centile) and length $68.6 \mathrm{~cm}$ ( $<10$ th centile).

At the age of 22 months she was admitted to a local hospital for investigation because she was below the 3rd centile for height and weight. Though the small head was again noted the child appeared bright and normal.

Routine blood and urine tests, blood urea nitrogen, glucose tolerance, serum calcium, phosphorus, potassium, and chlorides were all normal. Blood $\mathrm{CO}_{2}$ was 15-16 mEq/1, serum sodium 124-128 mEq/1, and urinary $p \mathrm{H}$ on several occasions was alkaline, so she was considered to have 'renal metabolic acidosis'. Skull radiographs showed no evidence of premature closure of sutures and she was not considered truly microcephalic. An intravenous pyelogram was normal. She was treated with dl-Methionine ${ }^{\star} 250 \mathrm{mg}$ twice a day for a period of over 3 years without any improvement in her growth.

She was admitted to The Hospital for Sick Children, Toronto, at age 5 years 2 months because of short stature. She appeared small but well proportionedher height was $93 \mathrm{~cm}$, weight $12.5 \mathrm{~kg}$, and head circumference $50 \mathrm{~cm}$ (all <3rd centile); otherwise the physical examination was negative (Fig. 1). Her IQ estimated by the Stanford-Binet test was 99 . Serum electrolytes, calcium, phosphorus, creatinine, blood urea nitrogen, glucose, and routine urinalysis were within normal limits as were the urinary and serum amino-acid chromatograms. The monitoring of blood and urinary $p \mathrm{H}$ and serum electrolytes during the first week of admission ruled out the possibility of metabolic acidosis. Radiographs of skull, chest, abdomen, and long bones were normal. The bone age was estimated to be 3 years.

Endocrine function was evaluated by tests for serum thyroxine $(6.6 \mu \%)$ and $T_{3}$ resin uptake $(28 \%)$. A metapyrone test gave a normal pituitary-adrenal response. The plasma cortisol values also showed normal diurnal variation. The growth hormone and insulin responses from an arginine infusion test and a 6-hour glucose tolerance test were also normal.

Dermatoglyphs were normal with a total digital ridge count of 77.

Blood grouping and red blood cell enzymes were studied in parents, sib, and patient but no pertinent gene loci were identified.

* Ninol. Frank W. Horner Ltd, Montreal, Quebec, Canada. 


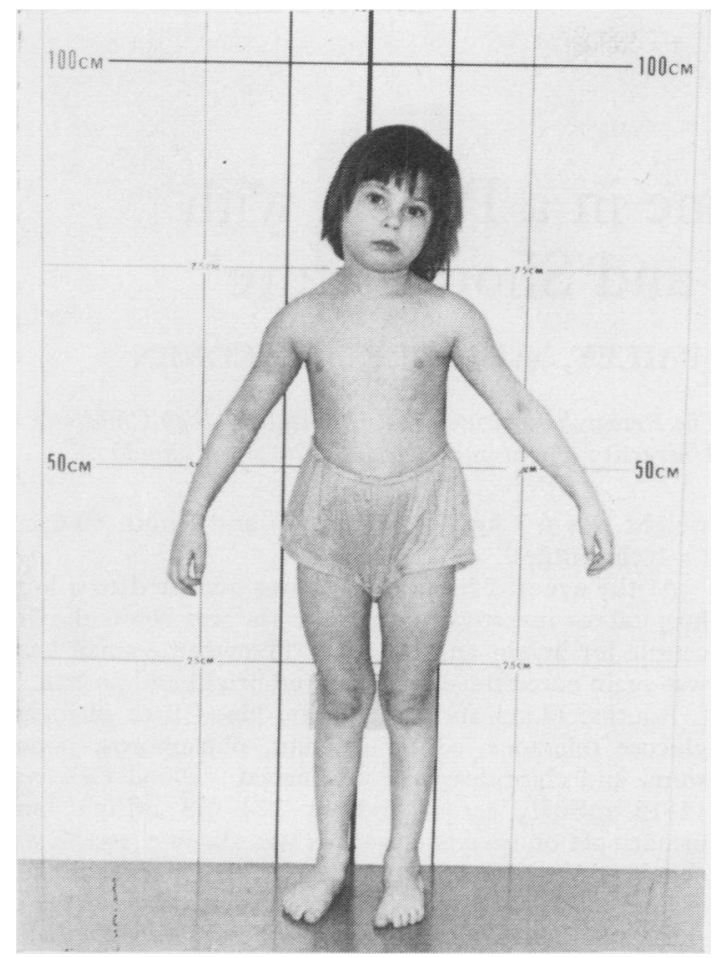

FIG. 1. The proposita aged 5 years 2 months, showing short stature and normal body proportion.

Cytogenetic Studies. Micromethod cultures of peripheral blood lymphocytes were made on 4 different occasions over a period of one year. Skin fibroblasts were cultured.

Autoradiographic studies with ${ }^{3} \mathrm{H}$-thymidine were made on blood to determine which of the B-group chromosomes was missing and hence which B-group chromosome was involved in the ring form. Sex chromatin studies were made on skin fibroblast cultures and buccal mucosa.

Of 490 cells of leucocyte cultures analysed (Table) most were found to have 46 chromosomes, the B-group having three normal members and a ring chromosome approximately the size of a D chromosome (Fig. 2).
Eighteen cells $(3.5 \%)$ had 46 chromosomes although they lacked a ring form and had only 3 B-group chromosomes. The complement of 46 was reached in ten of these cells by an extra chromosome either in C-group or in A-group, and in 8 by a dicentric or quadricentric chromosome (possibly explained by the reopening of the ring).

Of 15 cells studied from fibroblast culture, all had 46 chromosomes and included the ring as seen in the blood cultures.

In most cells the ring appeared monocentric and uniform in size but double ring, large rings, figure-of-eight forms, interlocking ring forms, and duplicate and quadruple rings were also seen (Fig. 3).

Lymphocytes from peripheral blood smears and lymphocytes from cultures without colcemid were found to have micronuclei which probably represent chromosome fragments resulting from breakage of an anaphase bridge.

Comparing the amount of labelling over a ring chromosome with that over normal chromosomes is difficult because of the shape and the overlapping chromatids. The labelling patterns of the remaining 3 members of Bgroup chromosomes were studied in 50 suitable cells. Two of the B chromosomes had early replicating long arms indicating they were members of pair No. 5, the 3rd B chromosome had heavily labelled long arms indicating that it was a member of pair No. 4, and so we can infer that the ring chromosome belonged to pair No. 4 (Miller et al, 1966). The ring itself was heavily labelledo (Fig. 2). A late labelling C-group chromosome was seeno in several cells, indicating normal $\mathrm{XX}$ sex chromosome complement.

A sex chromatin mass of normal size was found both in? cultured fibroblasts as well as in parallel cells of buccal mucosa. Micronuclei, interlocking, and double ring forms and abnormal chromosomes in some cells all indicate that the ring form is unstable.

Chromosome studies carried out on peripheral blood of parents and sib were normal.

\section{Discussion}

Ring chromosomes are known to behave irregularly at mitosis (Levan, 1956) so it is not surprising to find a few cells with multiple or variant ring forms in the present case.

During formation, some of the genetic material of

TABLE

ANALYSIS OF CELLS OF LEUCOCYTE AND FIBROBLAST CULTURES

\begin{tabular}{|c|c|c|c|c|c|c|c|}
\hline \multirow{2}{*}{$\begin{array}{c}\text { Tissue } \\
\text { Examined }\end{array}$} & \multicolumn{6}{|c|}{ Chromosome Counts } & \multirow{2}{*}{$\begin{array}{l}\text { Total } \\
\text { Cells }\end{array}$} \\
\hline & $45, \mathrm{~B}-, \mathrm{Br}+$ & $46, \mathrm{~B}-, \mathrm{Br}+$ & $\begin{array}{c}\text { 46, B-, Br- } \\
\text { A or } \mathrm{C}+\end{array}$ & 46,B - ,Bicen + & $47, \mathrm{~B}-, \mathrm{Br}+, \mathrm{Br}+$ & $4 n$ & \\
\hline $\begin{array}{c}\text { Blood } 1 \\
2 \\
3 \\
4 \\
\text { Skin }\end{array}$ & $\begin{array}{l}2 \\
1 \\
2 \\
2 \\
-\end{array}$ & $\begin{array}{r}95 \\
107 \\
60 \\
190 \\
15\end{array}$ & $\begin{array}{l}1 \\
2 \\
1 \\
6 \\
-\end{array}$ & $\begin{array}{l}\frac{1}{3} \\
\frac{4}{4}\end{array}$ & $\begin{array}{l}\overline{-} \\
\overline{1}\end{array}$ & $\begin{array}{l}2 \\
3 \\
\overline{7} \\
-\end{array}$ & $\begin{array}{r}101 \\
116 \\
63 \\
210 \\
15\end{array}$ \\
\hline
\end{tabular}




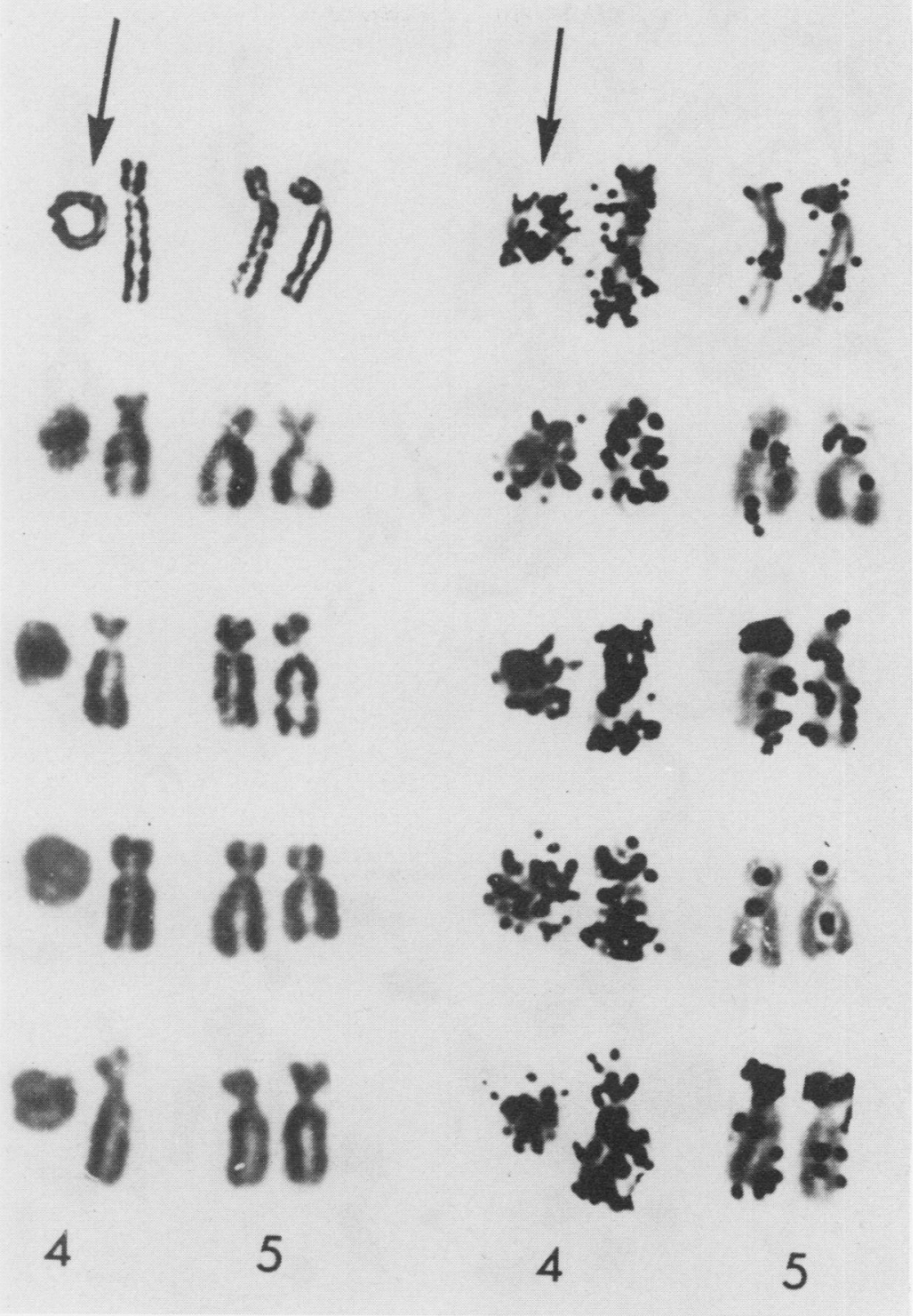

FIG. 2. Group B chromosomes showing representative autoradiographic findings.

a ring chromosome is lost. A ring chromosome thus represents a deletion in the genetic sense. Obviously the quantity of material lost and its site of origin in the chromosome determine the genetic constitution of the ring. Little wonder then, that even apparently similar ring chromosomes may be responsible for producing different clinical syndromes (Palmer, Fareed, and Merritt, 1967).

The short and long arms of a No. 4 chromosome are deleted in our patient. In 1964, Sidbury, Schmickel, and Gray reported a patient with a deletion of part of the short arm of a B-group chromosome who had severe somatic anomalies of the 'midline' type. Since then 15 cases of deletion of the short arm of a No. 4 chromosome have been reported and were reviewed by Miller et al (1970) and Taylor, Challacombe, and Howlett (1970). Our patient had no 'midline' defects or severe congenital malformations, 


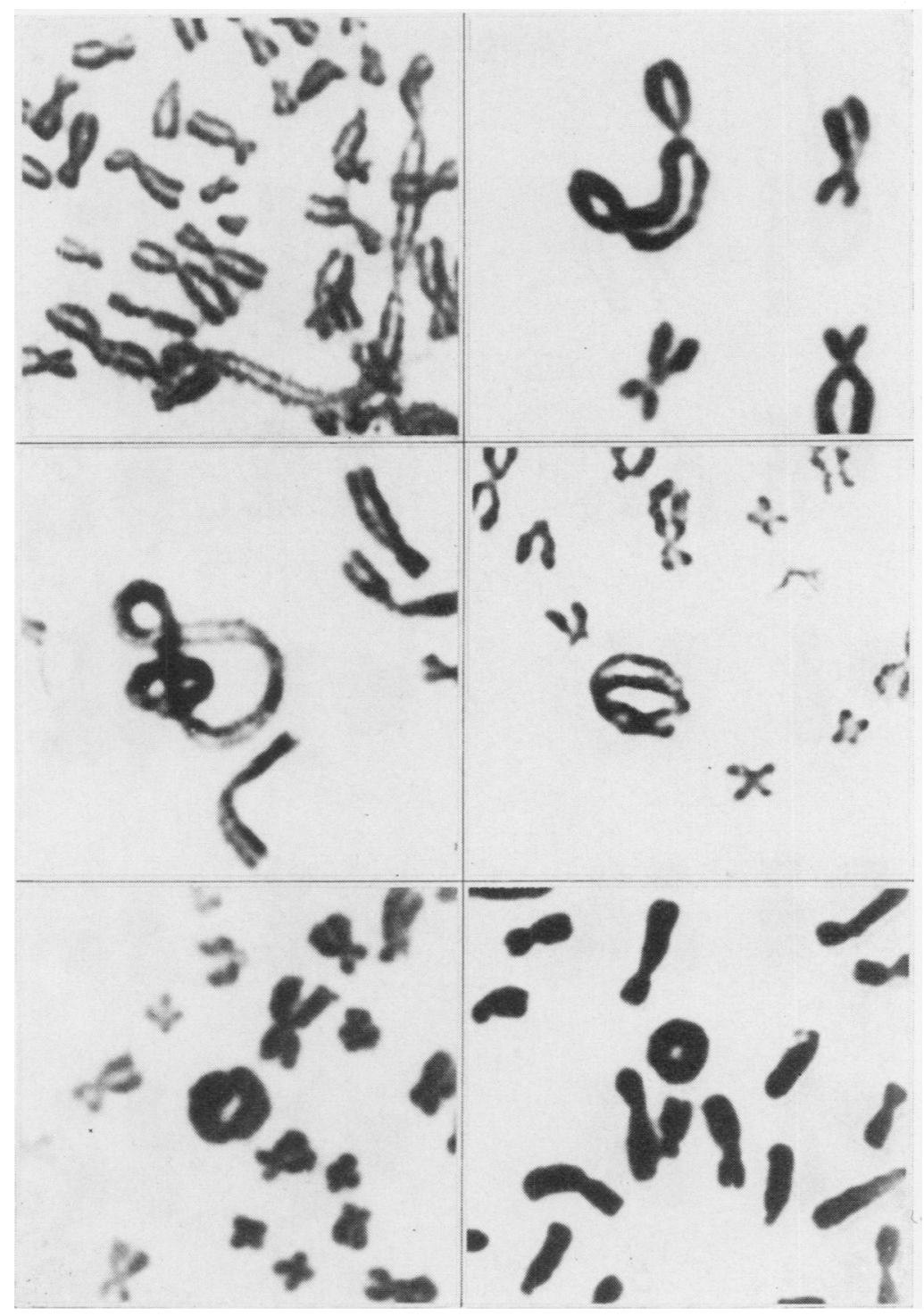

Fig. 3. Variant ring forms. Top two cells show multicentric chromosomes (explained by the reopening of the multicentric ring forms).

but her digital ridge count was low; her skeletal maturation and growth were retarded. It is possible that deletion of the long arm might modify clinical features due to deletion of short arm $(4 p-)$. The only other case of an autosomal ring reported in a patient with normal intelligence is also one of a ring-4 chromosome (Dallaire, 1969). However, Dallaire's patient had other congenital malformations.
Possibly the deletion in our patient is minimal and genetically inactive. Perhaps the deleted material is being translocated to other autosomes without producing obvious structural changes.

\section{Summary}

A 6-year-old child of normal intelligence but short stature, small head size, and delayed skeletal 
maturation had a karyotype monosomic for a Bgroup chromosome and an unstable ring chromosome which was identified by autoradiography to be a number 4. This child, in spite of deletion of part of the short arm of a No. 4 chromosome, had no midline defects usual in $4 \mathrm{p}$ - deletion syndrome.

The authors wish to thank Dr J. W. Rose and Dr R. D. Campbell for referring the patient and her relatives to us; Dr Eloise Giblett, King's County Central Blood Bank, Seattle, Washington for blood groupings and red blood cell enzymes; and Carol Crabtree for technical assistance.

\section{REFERENCES}

Carter, R., Baker, E., and Hayman, D. (1969). Congenital malformations associated with a ring 4 chromosome. fournal of Medical Genetics, 6, 224-227.

Dallaire, L. (1969). A ring B chromosome in a female with multiple skeletal abnormalities. Birth Defects: Original Article Series, V, 5, pp. 114-116. The National Foundation-March of Dimes, New York.

Faed, M., Stewart, A., and Keay, A. J. (1969. Chromosome abnormalities in two cases with bilateral radial element defects. fournal of Medical Genetics, 6, 342-346.

Hecht, F. (1969). Ring-4 chromosome: Ring autosomes, Lorelei of clinical-karyotype correlation and deletion mapping. Birth
Defects: Original Article Series, V, 5, pp. 106-113. The National Foundation-March of Dimes, New York.

Kistenmacher, M. L. and Punnett, H. H. (1970). Comparative behavior of ring chromosomes. American fournal of Human Genetics, 22, 304-318.

Levan, A. (1956). Self-perpetuating ring chromosome in two human tumours. Hereditas, Genetiskt Arkiv, 42, 366-372.

Miller, O. J., Breg, W. R., Warburton, D., Miller, D. A., Firschein, I. L., and Hirschhorn, K. (1966). Alternative DNA replication patterns associated with long arm length of chromosomes 4 and 5 in the cri du chat syndrome. Cytogenetics, 5, 137-151.

Miller, O. J., Breg, W. R., Warburton, D., Miller, D. A., deCapoa, A., Allderdice, P. W., Davis, J., Klinger, H. P., McGilvray, E., and Allen, F. H., Jr. (1970). Partial deletion of the short arm of chromosome No. $4(4 p-)$ : clinical studies in five unrelated patients. fournal of Pediatrics, 77, 792-801.

Palmer, C. G., Fareed, N., and Merritt, A. D. (1967). Ring chromosome 18 in a patient with multiple anomalies. Fournal of Medical Genetics, 4, 117-123.

Rohde, R. A. and Tompkins, R. (1965). 'Cri du Chat' due to a ring-B (5) chromosome. Lancet, 2, 1075-1076.

Sidbury, J. B., Jr., Schmickel, R. D., and Gray, M. (1964). Findings in a patient with apparent deletion of short arms on one of the $B$ group chromosomes. (Abstr.) fournal of Pediatrics, 65, 1098.

Steele, M. W., Breg, W. R., Eidelman, A. I., Lion, D. T., and Terzakis, T. A. (1966). A B-group ring chromosome with mosaicism in a newborn with cri du chat sydrome. Cytogenetics, $5,419-429$.

Taylor, A. I., Challacombe, D. N., and Howlett, R. M. (1970). Short-arm deletion, chromosome 4,(4p-), a syndrome? Annals of Human Genetics, 34, 137-144.

Wang, H.-C., Melnyk, J., McDonald, L. T., Uchida, I. A., Carr, D. H., and Goldberg, B. (1962). Ring chromosomes in human beings. Nature, 195, 733-734. 